\title{
Quando a raça e o gênero estão em questão: embates discursivos em rede social
}

\author{
Roberto Carlos da Silva Borges' ${ }^{1}$ (i) 0000-0001-9373-748X \\ Glenda Cristina Valim de Melo² 0000-0002-1878-5710
}

'Centro Federal de Educação Tecnológica Celso Suckow da Fonseca (CEFET/RJ), Línguas Estrangeiras Aplicadas às Negociações Internacionais e Programa de PósGraduação em Relações Étnico-Raciais, Rio de Janeiro, RJ, Brasil. 20271-110 ${ }^{2}$ Universidade Federal do Estado do Rio de Janeiro, Programa de pós-graduação em memória social, Rio de Janeiro, RJ, Brasil. 22290-240

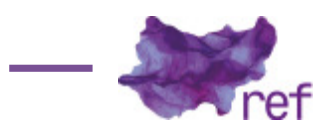

Resumo: Neste artigo, refletimos acerca de um conjunto de trocas interacionais realizadas nos perfis do Facebook de duas mulheres negras de destaque na mídia televisiva. Concentramos nossos esforços em produzir conhecimento sobre a (re)produção de discursos de injúria racial e de gênero num contexto on-line. Partindo da concepção de linguagem como ação, promovemos um diálogo com perspectivas teóricas relacionadas às questóes raciais. Os dados gerados nos permitem inferir que os atos de fala performativos de injúria racial e de gênero apontam para discursos e crenças que ainda constroem as mulheres negras, mesmo as bem-sucedidas, como 'animalescas' e 'inferiores' e cujos corpos estão 'naturalmente e sempre à disposição' de ataques violentos de diversas ordens, inclusive as verbais.

Palavras-chave: Raça; Gênero; Linguagem como Performance; Contexto On-line.

When Race and Gender are on Focus: Discursive Confrontations on Social Network Abstract:: The present text aims to reflect on interactional exchanges unfolded on two black women's Facebook profiles. Both have been on the spotlight on Brazilian television. Our focus is to produce knowledge regarding the discursive (re)production of race and gender-related slurs in an on-line context. Based on the assumption that language is action, we promote a dialogue with theoretical perspectives on 'race' and 'racism'. The data the study generated allow us to infer that the performative speech acts of racial and gender-related slurs point to discourses and beliefs which still construct black women as 'inferior' and 'bestial' - regardless their statuses - whose bodies are 'naturally always ready and available' to different kinds of (including verbal) assaults.

Keywords: Race; Gender; Language as Performance; Online Context.

\section{Introdução}

No Brasil, não há dificuldade de se perceber que há lugares específicos tanto para pessoas negras como para pessoas brancas frequentarem, mesmo que jamais tenha havido uma lei segregacionista para excluir e separar negros, brancos e indígenas: a forma como a questão racial e o racismo são historicamente construídos e agem neste contexto impediu e impede o acesso de pessoas negras às posições de aquisição, mando, poder de decisões e também aos espaços considerados sofisticados/ricos, a não ser que estejam lá para servir.

Assim, acreditamos que esse fenômeno seja um dentre os vários resultados sempre perversos de qualquer processo colonizador. No que se refere às terras brasileiras, tal resultado ainda é perceptível se considerarmos que não apenas persiste a exclusão de pessoas negras, como também permanece a nociva crença de que elas não ocupam posições de destaque porque não se esforçam o bastante, bem como a igualmente nociva ideia de que as mulheres negras são 
'naturalmente animais', 'inferiores' e, portanto, 'sempre disponíveis/dispostas' a quaisquer formas de violências.

No mundo contemporâneo, marcado por reflexividade sobre nós mesmos (Ben RAMPTON, 2006, p. 109-128), é imperioso reiterar, em toda instância espacial e temporal, que o termo 'raça' 'é uma construção política e social. É a categoria discursiva em torno da qual se organiza um sistema de poder socioeconômico, de exploração e de exclusão - ou seja, o racismo" (Stuart HALL, 2003, p. 66).

Sendo assim, abordar a questão racial, perpassada pelas questões de gênero, pode nos ajudar a compreender as práticas sociais locais e complexas em que vivemos. No entanto, qualquer análise da questão racial precisa levar em consideração a dificuldade de brasileiros e de brasileiras em reconhecerem em si próprios(as) comportamentos racistas. Uma pesquisa realizada há mais de vinte anos (Cleusa TURRA; Gustavo VENTURI, 1995), e ainda não ultrapassada, revelou que há racismo no Brasil, mas não existem racistas, instaurando-se um nítido paradoxo. Quando perguntados(as) sobre a existência do racismo, $90 \%$ dos(as) entrevistados(as) admitiram haver preconceito racial, mas $96 \%$ não se identificavam como 'racistas'. Corroborando o que apontam os dados dessa pesquisa, em entrevista à Revista Fórum (Camila Souza RAMOS; Glauco FARIA, 2012), o pesquisador Kabengele Munanga afirma que, no Brasil, o "racismo é um crime perfeito, porque a própria vítima é que é responsável pelo seu racismo [...]" (Não paginado).

Tendo em conta tais aspectos, este artigo visa refletir acerca de discursos de injúria racial e de gênero observados em trocas de mensagens postadas na rede social Facebook, especificamente nos perfis de duas mulheres negras de destaque na mídia televisiva. Optamos pelo contexto on-line, porque a web é um espaço de circulação de discursos diversos, constituindose em um espaço onde as pessoas estariam supostamente protegidas pela amplitude, pelo anonimato e pelas múltiplas possibilidades oferecidas pela rede, conforme Carolina Parreiras Silva (2008). Sabemos, no entanto, que essa crença é 'derrubada' pela computação que facilmente rastreia o $\mathbb{I P}^{1}$.

Ao situarmos esta discussão em contexto on-line, embasamo-nos na concepção de linguagem como ação ou performance (John Langshaw AUSTIN, [1962] 1990; Jacques DERRIDA, [1977] 1988), cujos efeitos são observados nos corpos e na vida social (Judith BUTLER, 1997). Sobre o conceito de raça, entendemos que se trata de uma construção social, histórica, discursiva e performativa, devendo ser estudada em intersecção com outros marcadores, como gênero e sexualidade, a fim de darmos conta de sua complexidade. Neste artigo, as perspectivas de raça e racismo estão embasadas em bell hooks (2015), Angela Davis ([1981] 2016), Hall (2003), Frantz Fanon ([1952] 2008), Munanga (2004) e Achille Mbembe ([2013] 2014). Já no que tange ao conceito de interseccionalidade, embasamo-nos na seguinte advertência de Kimberlé Crenshaw (2002):

A garantia de que todas as mulheres sejam beneficiadas pela ampliação da proteção dos direitos humanos baseados no gênero exige que se dê atenção às várias formas pelas quais o gênero intersecta-se com uma gama de outras identidades e ao modo pelo qual essas intersecções contribuem para a vulnerabilidade particular de diferentes grupos de mulheres. (p. 174)

Ainda no que diz respeito ao conceito de interseccionalidade e seu aproveitamento, recuperamos a seguinte observação de lan Kerner (2012), de modo a nela nos embasarmos também. Para o referido autor:

O reconhecimento de que formas sexuais de injustiça são, por um lado, análogas e, por outro, empiricamente entrelaçadas com outras formas de injustiça - como as relacionadas à "raça", etnia e religião - encontra nesse conceito sua expressão teórica. (p.45)

Posto isso, o presente artigo é composto por três seções: primeiramente, apresentamos uma breve genealogia da criminalização do racismo à brasileira; em seguida, abordamos a linguagem como ação ou performance; por fim, refletimos sobre os discursos de injúria racial e de gênero que interpretamos como 'emergentes' nas trocas de mensagens on-line realizadas no perfil do Facebook das duas mulheres negras.

\section{Racismo à brasileira}

Nos dias atuais, aparentemente, pouco se duvida de que o Brasil iniciou seu desenvolvimento econômico assentado no sistema escravocrata, cuja base foi, por séculos, o extenso tráfico de mulheres negras e de homens negros. Arrancadas de diversos países africanos, essas vidas negras formaram a 'mão de obra' que possibilitou e produziu diversos avanços, inclusive nas esferas socioeconômicas, mas dos quais nunca desfrutaram.

Entretanto, mesmo não restando dúvidas sobre os papéis primordiais das pessoas negras africanas, bem como de seus/suas descendentes, aqui escravizadas, parece ainda haver 'suspeitas'

'A sigla IP (do inglês 'Internet Protocol') refere-se à identificação única para cada computador conectado a uma rede. Sua função pode ser comparada a do CPF ou da carteira de identidade. 
ou 'desconfianças' quanto à relevância da questão racial e (da existência) do racismo, em especial nas análises sociais, econômicas, políticas e culturais sobre o Brasil.

Nosso objetivo, portanto, é operar na contramão das 'suspeitas' e fazermos coro às pessoas que 'confiam' na centralidade da raça e do racismo para/nas produções de conhecimento sobre as relações sociais brasileiras. Assim, interessa-nos compreender como essas relações têm sido construídas, levando em consideração os aspectos raciais e os do racismo. Dada a centralidade desses aspectos, julgamos incompleta qualquer análise social, econômica, política e cultural brasileira que os desconsidere. Afinal, como lembra Nilma Lino Gomes (2012, p.727-744), raça e racismo estruturam a sociedade e são institucionalizados de tal forma que parecem 'naturais'.

Por ser estruturante e estrutural em nossa sociedade e por se ter criado e mantido por séculos a narrativa mítica da democracia racial, pouco se produziu a respeito da rejeição à ocupação de posições de destaque por pessoas negras. Embora saibamos - por intermédio da história, da música, da literatura e das artes - que as tensões raciais no Brasil sempre existiram e que elas produziram manifestações racistas dirigidas às pessoas negras, esse tipo de manifestação tem recrudescido nos últimos anos.

Para que melhor se entenda esse processo específico, importa lembrar um caso que pode ter sido um catalisador do que presenciamos nos dias de hoje: a implantação de políticas de ações afirmativas para a inclusão de pessoas negras no ensino superior. Mesmo antes de serem consideradas constitucionais, as ações afirmativas para ingresso de pessoas negras no ensino superior geraram manifestações acirradas e fizeram emergir o racismo que, desde a abolição do trabalho escravo, se tenta negar sistematicamente. Essa política afirmativa, que questiona uma falsa meritocracia e, também, o privilégio de pessoas brancas ocuparem maciçamente, há séculos, os bancos das instituições públicas de ensino superior do Brasil, fez ruir o tão admirado 'mito da democracia racial' e trouxe à tona uma quantidade de denúncias de injúrias raciais como ainda não se tinha visto por aqui. As denúncias de injúria racial e de crime de racismo, até então, eram casos isolados e/ou apagados socialmente, o que ratificava a sensação ilusória de que o Brasil fosse, de fato, o paraíso da democracia racial.

Embora já tivéssemos leis específicas - tais como: a Lei n. 1.390/51 (BRASIL, 1951), também conhecida como Lei Afonso Arinos, que inclui "entre as contravenções penais a prática dos atos resultantes de preconceito de raça e cor" (p. 1); o inciso XLII do Artigo $5^{\circ}$ da Constituição Federal de 1988 (BRASIL, 2017) que estabelece que "a prática do racismo constitui crime inafiançável e imprescritível, sujeito à pena de reclusão, nos termos da lei” (p. 20), e a Lei n.7.716/89, também chamada de Lei Caó, que define os crimes resultantes de preconceito de raça e de cor-, nenhuma lei antirracista foi suficiente para impedir que pessoas não negras agredissem estudantes negros e negras ingressantes nas universidades públicas pelo sistema de cotas raciais. As pessoas não negras entendiam como usurpação de seus direitos o ingresso daqueles sujeitos pelo sistema de cotas, conforme se pode inferir em diversos casos de injúrias raciais relatados em jornais (Luís SOARES, 2012; Marco WEISSHEIMER, 2016, on-line, sem paginação).

Em paralelo aos crimes raciais e às injúrias raciais praticadas off-line, acirram-se também as manifestações on-line. Embora não nos seja possível precisar o momento em que as atitudes de cunho racista se intensificam em ambientes on-line, o argumento de que há, de fato, um aumento, se sustenta pela necessária criação do Projeto de Lei do Senado (PLS) n.80/2016 que "dispõe sobre a prática de crime de discriminação ou preconceito de raça, cor, etnia, religião ou procedência nacional por intermédio da rede Internet ou de outras redes de computadores de acesso público" (BRASIL, 2016, p.1).

Se buscarmos explicações para essa inflexão explícita e tão radical nas relações raciais no Brasil, talvez algumas mudanças históricas importantes, ocorridas nos limites deste século, nos tragam alguns subsídios para análise, entre as quais podemos citar: a) a III Conferência Mundial de Combate ao Racismo, Discriminação Racial, Xenofobia e Intolerância Correlata, quando o governo do Brasil, ao se tornar signatário da Declaração de Durban (DURBAN, 2001), em 2001, reconheceu diante de outras lideranças mundiais que este país é racista e passou a assumir que o racismo é um problema a ser combatido; b) dois anos depois, em 2003, a alteração da Lei $n$. 9.394/96 - Lei de Diretrizes e Bases da Educação Nacional (BRASIL, 1996) - em seus Artigos 26A e 79B, que tornou obrigatória a temática História e Cultura Afro-brasileira, bem como o estudo "da História da África e dos Africanos, a luta dos negros no Brasil, a cultura negra brasileira e o negro na formação da sociedade nacional, resgatando a contribuição do povo negro nas áreas social, econômica e política pertinentes à História do Brasil" (BRASIL, 2003, p.1); c) a institucionalização das cotas raciais para pessoas negras, em primeiro lugar na Universidade do Estado do Rio de Janeiro (UERJ), seguida pela Universidade de Brasília (UnB), e, depois, aplicada por outras universidades até se transformar em lei federal (SUPREMO TRIBUNAL FEDERAL, 2012).

Além disso, foram criados programas como o Fundo de Financiamento Estudantil (FIES) e o Programa Universidade para Todos (PROUNI), que promoveram o acesso de um grande número de pessoas negras e pobres ao ensino superior. Essas alterações podem ser entendidas como uma 
revolução nacional - ou parte de uma - que tem como resultado a incorporação de uma categoria historicamente excluída em posições ainda não alcançadas anteriormente. Ao proporcionar o ingresso de pessoas negras ao ensino superior, não mais por exceção, o status quo de parte significativa da população "branca" é abalado e provoca reações incomuns até então.

Se somarmos a isso um grande movimento de conscientização política a respeito dos direitos e da história de pessoas negras promovido pelos mais diversos núcleos - como os Núcleos de Estudos Afro-Brasileiros e Indígenas (NEABIs) em universidades brasileiras (Eugenia Portela Siqueira MARQUES; Wilker Solidade da SILVA, 2016, p. 89-108) e os Coletivos de Negros e Negras, que acolhem os/as estudantes negros(as) quando chegam às universidades -, teremos sólidas evidências que apontam para a entrada de atores cujos destinos, faz pouco tempo, eram apenas os lugares de explorações e de subalternidades na cena social. Em paralelo, a crescente quantidade de denúncias de crimes de racismo e de injúrias raciais pode ser o indício de que as pessoas negras não estão mais dispostas a se calar diante de agressões e de manifestações de discriminação racial.

Em se tratando especificamente de contextos on-line, Fabiana Moraes (2013) elucida que:

Se, no mundo sensível [sic], o racismo ou injúria racial ainda encontram barreiras para ser identificados como tal, no espaço digital, apesar dos tantos exemplos explícitos de discriminação, percebe-se uma dificuldade ainda maior da aplicabilidade da lei. $\mathrm{O}$ artigo 20 da Lei 7.716/89 é bastante claro: é crime "Praticar, induzir ou incitar, pelos meios de comunicação social ou por publicação de qualquer natureza, a discriminação ou preconceito de raça, por religião, etnia ou procedência nacional" (artigo incluído pela Lei n 8.081, de 21/9/1990). A pena: reclusão de dois a cinco anos. (p. 62)

É importante observarmos que o Brasil se constitui como o quinto país do mundo em número de usuários de internet e, mesmo assim, só tivemos o primeiro processo por racismo em redes virtuais em 2006, acontecido na rede social Orkut (MORAES, 2013). Esse caso se tornou emblemático devido à aplicação das medidas punitivas: os criminosos foram presos. Muitos outros casos se seguiram a esse e podem ser conferidos em MORAES (2013), seja contra as pessoas negras e não negras que se destacam nacionalmente, como atrizes e jogadores de futebol, seja contra cidadãs e cidadãos comuns.

O racismo, estrutural e estruturante (FANON, [1952] 2008), bem como manifestações discriminatórias - contra as mulheres, por exemplo - são construídos pela linguagem. Assim, o racismo e quaisquer formas de discriminações são construções situadas histórica, social, cultural, discursiva e performativamente. Ao produzirmos e/ou reproduzirmos textos racistas, estamos realizando ações pela linguagem, como veremos a seguir.

\section{Linguagem como performance, gênero e raça}

Assim como o racismo, o machismo e a misoginia também são fenômenos estruturantes da sociedade. O feminismo surgiu como um movimento de luta contra a opressão falocêntrica. No entanto, como aponta hooks (2015), nem mesmo o movimento feminista da década de 1960 tratou as mulheres negras como mulheres, pois, como explica a autora, ao ter como preceito central a afirmação de que todas as mulheres são oprimidas, o movimento daquela época tanto desconsiderou a diversidade de categorias, tais como raça, classe e sexualidade, na construção do 'ser mulher' quanto não percebeu como essas categorias, uma vez associadas, sequestram, em diferentes graus, as alternativas que possuem as mulheres negras. hooks (2015) ainda argumenta que as mulheres negras:

[...] estão em uma posição incomum nesta sociedade, pois não só estamos coletivamente na parte inferior da escada do trabalho, mas nossa condição social geral é inferior à de qualquer outro grupo. Ocupando essa posição, suportamos o fardo da opressão machista, racista e classista. (p. 207)

Como aponta Danúbia de Andrade Fernandes (2016, p 692), ao falar de Saartjie, a Vênus Hottentote, a articulação complexa entre gênero e raça tem como fim uma dupla e, podemos dizer, perversa alteridade, que coloca as mulheres negras duplamente no lugar de 'menos' humanas, ou seja, a desumanização por serem negras e por serem mulheres. Nessa 'lógica', mulheres negras são mais 'desumanas' e 'desimportantes'.

Para entendermos como ocorre essa dupla desumanização - ser mulher e ser negra -, torna-se imperioso compreendermos o funcionamento e a relevância da linguagem na construção da 'desimportância' de tais vidas nas práticas sociais, visto que construímos vidas e elencamos aquelas que de fato são 'importantes' também pela e na linguagem. De acordo com Butler (2015):

[...] antes, ser um corpo é estar exposto a uma modelagem e a uma forma social, e isso é o que faz da ontologia do corpo uma ontologia social. Em outras palavras, o corpo é exposto a forças articuladas social e politicamente, bem como as exigências de sociabilidades - incluindo a 
linguagem, o trabalho e o desejo -, que tornam a subsistência e a prosperidade do corpo possíveis. (p.15-16)

Portanto, é pelo discurso que construímos as práticas sociais, legitimamos certas vidas, deslegitimamos outras, elegemos ou contestamos certas naturalizações da posição/colocação social de alguns corpos e de saberes hegemônicos, legitimamos certas existências de umas pessoas em detrimento às existências de outras.

Dessa forma, cumpre ressaltar que, neste estudo, a linguagem é compreendida tanto como ação ou performance, de modo que estamos seguindo a proposta sistematizada por John Langshaw Austin ([1962] 1990). Para o filósofo, a linguagem são atos de fala que, quando enunciados, realizam ações, fazem 'coisas' no mundo. Logo, para ele, a linguagem não apenas descreve, ela também 'faz'. Esses atos de fala, na perspectiva austiniana, inicialmente seriam caracterizados como constatativos e performativos. Os primeiros teriam a função de descrever e os segundos a de realizar uma ação. O autor ainda indica que, para que os atos de fala sejam realizáveis, haveria condições especiais, como a veracidade da ação, a credibilidade do enunciador, a intenção de verdade na ação.

Contudo, após rever sua própria perspectiva teórica, Austin afirma que todos os atos de fala são performativos - exceto os estiolamentos, como a ficção -, e os caracteriza como locucionários, ilocucionários e perlocucionários. Nesta investigação, interessam-nos os últimos, porque tratam dos efeitos de tais atos nas práticas sociais como veremos ao longo desta reflexão.

Derrida ([1977] 1988) parte da perspectiva de que todos os atos de fala são performativos, incluindo os estiolamentos, e que realizam ações, o que Alastair Pennycook (2007) compreende como performance. Além disso, o filósofo argelino inova ao explicar como os atos de fala são naturalizados pela iterabilidade e também pela citacionalidade. Esse processo proposto por Derrida é compreendido como a repetição que pode criar ou produzir a ideia de 'substância' ao que é dito ou de 'verdade'. Vejamos cada caso.

Com relação à iterabilidade, pensemos metaforicamente que essa apresenta duas faces: o performativo e a performatividade. Por meio da iterabilidade, a persistente repetição dos atos de fala performativos aponta para ou indexa memórias, crenças, valores e discursos que há séculos têm sistematicamente inferiorizado as mulheres negras. Dá-se o nome de performativo a essa primeira face da iterabilidade.

Explicando melhor, segue um exemplo: quando nos deparamos com mulheres negras de destaque na mídia, em pleno século XXI, sendo agredidas pela linguagem ao serem chamadas de "macacas" e de "escravas", ao serem apontadas como possuidoras de "cabelo ruim", podemos observar que tais índices linguísticos têm sido repetidos não apenas em perfis de redes sociais como também no mundo off-line. Exemplos comprovam essa observação e podem ser encontrados nos mais variados setores da sociedade, sendo o esporte um dentre muitos. (Luiz Filipe BARBOZA; Marcelo ALVES, s/d, on-line). Eis a primeira face da iterabilidade: o performativo.

A outra face da iterabilidade, chamada de performatividade, é a repetição que pode falhar. Ocorrendo a falha, surge nesse processo o novo, o criativo, o transgressivo, ou seja, a performatividade.

Por fim, a citacionalidade seria a citação de textos ou discursos no processo de iterabilidade. Na perspectiva de linguagem como performance, portanto, podemos considerar que a linguagem está para além da descrição: são atos de fala corpóreos que também fazem 'coisas' no mundo social. Segundo Butler (1997):

Fazemos coisas com a linguagem, produzimos efeitos com a linguagem, e fazemos coisas à linguagem, mas a linguagem também é aquilo que fazemos. Linguagem é um nome para nossa ação: tanto o 'quê' fazemos (o nome para a ação que caracteristicamente encenamos) tanto aquilo que fazemos acontecer, o ato e suas consequências. (p.8)

Considerando ainda a perspectiva butleriana, que está embasada na perspectiva de linguagem de Austin ([1962] 1990) e de Derrida ([1977] 1988), podemos argumentar que nossos corpos são construídos pelos processos de iterabilidade e de citacionalidade, ou seja, na e pela repetição de atos de fala e corpóreos que circulam nas práticas sociais que, por seu turno, naturalizam algumas ações. Certos discursos, em outras palavras, compreendidos como enquadres por Butler (1997), regulamentam nossos modos de agir e nossa interpretação.

Considerando os estudos sobre gênero, especificamente em autoras como Butler ([1990] 1999), bell hooks (1994), Joan Scott ([1986] 1995, p.71-99), Davis ([1981] 2016); partindo dos pressupostos de que linguagem é performance e de que raça e gênero são invenções históricas, culturais e sociais situadas que se constroem na linguagem - cujos efeitos marcam os corpos -, pressupomos, então, que pelo processo de iterabilidade e de citacionalidade de atos de fala, normatizam-se regras de raça e gênero que informam 'o que é' e 'como deve ser' uma pessoa negra, não negra, homem, mulher e pessoa trans. Butler ([1990] 1999), em Problemas de Gênero, salienta a importância da linguagem, especificamente dos atos de fala, para a construção de gênero que ocorre por meio 
da repetição. É pela repetição que se define e se 'naturaliza' que uma menina deve usar rosa e o menino, azul. Da mesma forma, é pela repetição que se definem os espaços, os comportamentos, as estéticas possíveis e 'esperadas' das pessoas negras e das pessoas não negras.

Segundo a filósofa norte-americana, há um sistema, uma morfologia e uma regulação que sustentam esta normatização perversa: as vidas femininas valem menos que as vidas masculinas. Acrescentamos que, se essas vidas femininas tiverem em seus corpos as marcas que fenotipicamente marcam a raça negra, por um viés interseccional, tais vidas negras passam a valer duplamente menos.

Para Butler ([1990] 1999), quando a questão do gênero está em tela, encontramos seu núcleo, "que é produzido pela regulação dos atributos segundo linhas de coerência culturalmente estabelecidas" (p. 55). Importante também levar em consideração o fato de o gênero ser construído, conforme Scott ([1986] 1995, p. 71-99), na economia, no mercado de trabalho, na organização política, na educação, na mídia e na igreja. Em nossa perspectiva, a construção da noção de raça perfaz a mesma trajetória apontada por essa autora.

A título de exemplificação, consideremos o contexto político brasileiro em 2017: ao analisarmos a constituição de um primeiro escalão político formado majoritariamente por homens brancos, constatamos o que se constrói - se destrói ou se desconstrói - para todas as pessoas brasileiras quando o assunto é raça e gênero na política.

Destacamos, ainda, que dentro do contexto feminino, algumas vidas são mais relevantes que outras numa mirada interseccional. Isso pode ser observado nas práticas sociais em que mulheres cis, brancas, de classe média são compreendidas como 'superiores' às mulheres, cis ou trans, latinas, negras, asiáticas, de classe média ou de classes economicamente desfavorecidas, por exemplo.

No que tange ao contexto feminino no Brasil, é possível nos depararmos com mulheres negras, cis, atrizes ou jornalistas de prestígio, de classe média ou alta, sendo violentamente atacadas nas redes sociais. Essa intersecção de gênero, raça e classe social nos mostra a importância de articular tais marcadores para compreendermos a complexidade do machismo, do racismo, da homofobia e de tantos outros crimes cometidos contra mulheres que se distanciam dos padrões estabelecidos pela branquidade e/ou heteronormatividade.

Se voltarmos na história, dentro do próprio feminismo, segundo bell hooks (1994) e Davis ([1981] 2016), havia uma diferença de tratamento marcada pelo racismo entre as mulheres brancas e mulheres negras. Quando as primeiras construíram suas reivindicações via luta feministas, as mulheres negras continuavam esquecidas e tinham de enfrentar o racismo das mulheres brancas. Além disso, as mulheres negras, filhas da diáspora, passaram por um processo diferente de construção de gênero, visto que ele está articulado à raça e, conforme Mbembe ([2013] 2014), a raça seria sempre voltada às pessoas negras, ou seja, sempre o outro. Esse 'outro', aqui, é a mulher negra.

A perspectiva da interseccionalidade nos traz 'lentes de aumento' que possibilitam a observação das relações de poder que permeiam essas intersecções, que não se restringem à interposição de categorias, como assevera Scott ([1986] 1995, p.71-99). Quando interseccionamos gênero, raça e sexualidade, vidas de mulheres negras, latinas, asiáticas, indígenas - e suas descendentes -, cis, trans, hetero(homo)afetivas ou bissexuais valem duplamente menos que vidas de mulheres brancas, cis, trans, (hetero)homoafetivas ou bissexuais.

Segundo Butler ([2009] 2015), "a capacidade epistemológica de apreender uma vida é parcialmente dependente de que essa vida seja produzida de acordo com as normas que a caracterizam como uma vida, ou melhor dizendo, como parte da vida" (p.16). As vidas dessas mulheres citadas acima, e duplamente oprimidas, são construídas e constituídas fora da norma do que seria 'vida' ou em outras palavras: a vida de mulheres brancas, cis, de classe média.

\section{Os discursos de injúria racial e de misoginia que circulam nas redes sociais}

Este estudo se insere no âmbito da pesquisa qualitativo-interpretativista, pois compreende o pesquisar pelo viés sócio-histórico, entendendo que a produção de verdades a respeito dos objetos de conhecimento são produções discursivas situadas (Luiz Paulo da MOITA LOPES, 1994, p.331). Além disso, ele se embasa nos estudos etnográficos de internet, por isso é de cunho etnográfico, na perspectiva adotada por Christine Hine (2000; 2005).

A web é um espaço em que circula uma diversidade de textos e de discursos. Atentos ao que ocorre neste mundo digital, percebemos que no ano de 2015 algumas mulheres negras e profissionais da grande mídia televisiva passaram a sofrer constantemente ataques de caráter racista nas redes sociais. Essas mulheres são bem-sucedidas em suas carreiras e apresentam um determinado padrão de beleza negra.

A partir disso, passamos a observar este fenômeno específico ao longo de 2015, salvando as postagens sobre este fato para futura geração de dados. Salientamos que nos interessam este público específico, porque são pessoas que romperam muitas barreiras impostas tanto pelo 
machismo/patriarcado como pelo racismo, se observamos que na grande mídia há pouca representatividade de mulheres negras. Com os dados em mãos, optamos por analisar aqui os excertos mais agressivos e ofensivos, além de mais populares ao cotidiano das pessoas negras em contexto brasileiro.

No dia 31 de outubro de 2015, por volta das 14 horas, uma das mulheres negras cujo perfil analisamos - atriz, com nível superior completo, considerada uma importante estrela televisiva, protagonista em mais de uma novela de audiência e em outros programas de TV - após publicar uma foto de seu rosto com seus cabelos soltos, foi surpreendida por algumas manifestações violentas e de cunho racista que apresentaremos a seguir² sob o título de 'Interações A'.

Interações A:

$\mathrm{P1}$ : Já voltou da senzala? [103 curtidas]

P2: vai lavar louça com esse cabelo [120 curtidas]

P1: Quem postou a foto desse gorila no Facebook? [86 curtidas]

P3: linda 3 [51 curtidas]

P2: nao sabia que no zoologico tinha camera [178 curtidas]

P4: cabelo de saco [174 curtidas]

P5: CABELO DE LAVAR LOUÇA KKKK ESPONJAÇO KKKKK [118 curtidas]

P6: Esse cabelo de esfregão [58 curtidas]

P7: SALVE REDE GLOBO [58 curtidas]

P8: cabelo de bombril [75 curtidas]

P9: os Traficante pira, chei de pó na cara [52 curtidas]

P5: O Facebookn deveria ter aceitado sua Pub, fica postando essas foto preta aí, aii n, deveria estar cortando cana [50 curtidas]

Se observarmos os índices linguísticos na perspectiva de Michael Silverstein (1985) compreendidas como marcas linguísticas que indicam ações semióticas -, há uma repetição de atos de fala que caracterizam negativamente o cabelo da atriz: "cabelo de esfregão", "cabelo de lavar louça", "esponjaço kkkkk", "cabelo de saco" e "cabelo de bombril".

Os índices linguísticos selecionados, em sua maioria, indicam justamente um ataque à construção da identidade negra, porque suas características não correspondem àquilo que tem sido construído como 'padrão/modelo'. Esses índices podem revelar o desejo de agredir, de humilhar e de desumanizar uma pessoa/vida, como argumenta Maria Aparecida Silva Bento (2002):

O primeiro passo da exclusão moral é a desvalorização do outro como pessoa e, no limite, como ser humano. Os excluídos moralmente são considerados sem valor, indignos e, portanto, passíveis de serem prejudicados e explorados. (p.29)

Os índices linguísticos atribuem ao cabelo da atriz características não humanas e objetificadoras. Segundo Gomes (2003, p.137-150), os cabelos são ícones na construção estética das pessoas em geral e têm sido um importante elemento de afirmação identitária das mulheres negras. Por outro lado, esse mesmo ícone também é um instrumento utilizado para discriminar essas mesmas mulheres, pois, atacar a estética de uma pessoa é atacar sua construção identitária.

Cabe observar que todas essas ações são realizadas por meio da linguagem e são disponibilizadas em perfis públicos de redes sociais. Como seus/suas autores(as) expõem seus rostos e suas fotos, pode-se levar à crença de que os atos dos/das comentaristas do perfil são ações socialmente aceitáveis. É importante também ressaltar que na reprodução acima das nove postagens, a maioria foi produzida por pessoas cujas fotos parecem ser de homens e apenas uma por uma pessoa que parece ser uma mulher. Desse total, somente dois comentários aparentam não se constituírem como agressão à atriz: os índices linguísticos que os marcam são "linda", elogiando a beleza da atriz, e "Salve Rede Globo", mostrando o local de trabalho da autora. Entretanto, reconhecemos que é possível que tais índices tenham sido utilizados de forma irônica.

Ampliando nossa análise para além das performances identitárias, podemos dizer que as ações repetidas no e pelo discurso constroem o mundo social em que estamos e têm efeitos nos

${ }^{2}$ Optamos por transcrever as postagens e buscamos uma proximidade com suas formas textuais - ortografia, sintaxe e pontuação - e formatos - uso de caixa alta, de símbolos etc. Por uma questão ética, transformamos os nomes dos autores e das autoras das postagens em siglas numeradas de modo a preservar-lhes a identidade e impossibilitar qualquer tentativa de rastreamento e/ou reconhecimento. Desse modo, 'P1' é a sigla para 'Participante 1', 'P2' para 'Participante 2' e assim sucessivamente. Por fim, sinalizamos entre colchetes a quantidade de 'curtidas' ['likes'] que recebeu cada uma das mensagens transcritas, tendo a preparação deste texto como tempo-limite de geração de dados. 
corpos e nas vidas, pois essas ações repetitivas indicam, também, as relações de poder exercidas nos contextos em que se inserem (Joana Plaza PINTO, 2007, p. 1-26).

Dito de outro modo, há toda uma morfologia que reconhece, trata e constrói discursiva, performativa, cultural e historicamente as mulheres negras, desde a escravização, como 'objetos', 'desumanizadas' e 'inferiores'. Ainda que circulem crenças e discursos positivos sobre tais mulheres nas práticas sociais cotidianas, o racismo, estrutural e estruturante no Brasil, tem sido mantido na linguagem e em suas ações.

Além dos índices apontados anteriormente, há outros que atacam a autoestima e desqualificam a atriz com a mesma 'naturalidade' dos anteriores. Seguem alguns exemplos de tais índices: "Já voltou da senzala?", "Quem postou a foto desse gorila no Facebook?", "nao sabia que zoologico tinha camera", "Os Traficante pira, chei de pó na cara".

Pela perspectiva derridiana de iterabilidade, tais atos de fala performativos reforçam e naturalizam discursos que visam desqualificar e desumanizar as vidas dos corpos negros, especificamente, das mulheres negras que se encontram em posição de projeção nacional e de exercício de poder. Mesmo que - e, principalmente 'porque' - a atriz alvejada pelas injúrias tenha participado de várias telenovelas, programas de televisão e tenha estampado capas de revistas de prestígio, contribuindo, dessa forma, para uma representatividade positiva do negro, ela não está, de forma alguma, 'protegida' de ataques violentos, inclusive os de ordem verbal. Como Lia Vainer Schucman (2014) ressalta:

O fato de o preconceito racial recair sobre a população não branca está diretamente relacionado ao fato de os privilégios raciais estarem associados aos brancos. O branco não é apenas favorecido nessa estrutura racializada, mas é também produtor ativo dessa estrutura, através dos mecanismos mais diretos de discriminação e da produção de um discurso que propaga a democracia racial e o branqueamento. (p.26)

A mesma animalização e desumanização de mulheres negras podem ser identificadas pelo emprego dos índices linguísticos predicativos "macaca" e "carvão" em outras postagens publicadas no Facebook de um jornal televisivo, no dia 03 de julho de 2015.

Desta vez, os ataques verbais tiveram por 'alvo' uma segunda mulher negra profissional do jornalismo. Como veremos nas 'Interações B', ela sofreu ataques violentos muito próximos aos sofridos por primeira mulher, transcritos e analisados anteriormente. Vejamos:

\section{Interações B}

P1: Só conseguiu emprego no JN Por causa das cotas preta imunda [36 curtidas]

P1: Tempo branco? mentira, sua preta. [41 curtidas]

P2: Só conseguiu emprego no JN Por causa das cotas, preta macaca [85 curtidas]

P3: Qual é band-aid de preto?

R: Fita isolante [ 17 curtidas]

P4: Não bebo café pra não ter intimidade com preto. [71 curtidas]

P5: Ela ja nasceu de luto [51 curtidas]

P3: O que são 100000000 de pretos na lua?

R: Um eclipse total! [28 curtidas]

P6: Em pleno século 2015 ainda temos preto na TV [9 curtidas]

P7: Só foi ela chegar aí que o tempo ficou seco igualmente a um carvão em cinzas [8 curtidas]

Considerando que, conforme Gayle Rubin (2011), os textos são parte de um repertório de conversas, de um ambiente político e produzidos "particularmente em momentos históricos" e "com horizontes específicos de possibilidades" (p. 1), as trocas interacionais analisadas aqui, todas publicadas e (re)produzidas na rede social Facebook permitem-nos vislumbrar um ambiente sociopolítico cujos horizontes e possibilidades não são nada animadores. Todos esses discursos apontam para memórias, crenças e discursos que naturalizam a mulher negra como 'inferior' desde o processo de escravização ocorrido há séculos. Nessa memória construída pela/na linguagem e pela repetição, tais discursos seguem percorrendo trajetórias nos tempos e nos espaços.

Em resposta a um de seus posts, no qual ela aparecia exercendo seu ofício, encontramos mais um rol de ofensas dirigidas a ela, uma mulher negra, que se tornou famosa ao apresentar 0 segmento sobre o clima/tempo no Jornal Nacional, na empresa televisiva de maior audiência do Brasil, a mesma onde a outra mulher trabalha. As marcas linguísticas levantadas nos posts mostram que tais agressões procuram atingir, questionar e pôr em xeque a forma como a apresentadora ingressou na emissora em que trabalha para ocupar sua posição, entendida como posição de 
destaque, e, dessa forma, questionar sua capacidade e competência. Vale salientar que questionar a competência de pessoas negras também é uma das múltiplas estratégias racistas para desqualificálas.

Aqui, para atingir Maria Júlia, encontramos menção às cotas raciais, interpretadas por algumas pessoas - de forma muito equivocada - como ações que possibilitam o ingresso de sujeitos 'menos capazes' - ou de todo 'incapazes'- aos lugares que ocupam. Como dissemos anteriormente, as cotas raciais foram e continuam sendo um catalisador de disputas políticas, sociais e discursivas a respeito de mérito, de legitimidade, de exploração e de subalternização de pessoas negras e de privilégios de pessoas brancas, dentre diversos outros temas políticos, sociais, de raça e de gênero também.

Os excertos "Só conseguiu emprego no JN Por causa das cotas preta imunda" e "Só conseguiu emprego no JN Por causa das cotas, preta macaca", ao associarem seu ingresso por intermédio de políticas de ações afirmativas, mostram uma tentativa de desqualificação da apresentadora, ao mesmo tempo em que expõem a ignorância social e política de quem produziu as agressões. Nesse sentido, vale reforçar: as cotas raciais têm garantido o ingresso de pessoas negras a posições sociais não atingidas até pouco tempo atrás. A inviabilidade de alcance a tais posições era/é uma das consequências do sistema opressor que exclui pessoas negras de lugares de mando, de poder e de acesso à educação.

Outros índices que apontam para tentativas de desqualificar a capacidade e o valor da jornalista/apresentadora são estes: "Tempo branco? mentira, sua preta" e "Só foi ela chegar aí que o tempo ficou seco igualmente a um carvão em cinzas". Ambos remetem à meteorologia e a seu campo semântico e desmerecem a função e a posição de Maria Júlia na TV.

Ainda há um elenco de índices retóricos, construídos como charadas/enigmas, supostamente engraçados, a serem decifrados e que apontam para piadas de mau gosto, tais como: "Não bebo café pra não ter intimidade com preto" e "Ela ja nasceu de luto". Duas 'charadas-piadas' foram postadas pelo mesmo autor (P3): "Qual é band-aid de preto? R: Fita isolante" e "O que são 1000000 pretos na lua? R: Um eclipse total!!!" Há, ainda, o seguinte post 'humorístico': "Em pleno século 2015 [sic] ainda temos preto na TV".

Observamos aqui que há desumanização e inferiorização da jornalista pelos atos de fala performativos 'humorísticos', técnica retórica midiática comumente utilizada para deslegitimar/ desqualificar. Assim, os atos performativos como piadas e charadas, ou seja, supostas brincadeiras, produzem efeitos semânticos racistas e indexicam discursos que desejam inferiorizar negros e negras. Butler ([2009] 2015) afirma que algumas vidas são mais precárias que outras e que só algumas perdas humanas podem ser lamentadas e choradas. Ser um corpo negro é estar exposto a memórias, crenças, discursos, "a uma modelagem e a uma forma social, é isso que faz da ontologia do corpo uma ontologia social" (p. 15).

Como nos informa Schucman (2014, p. 42), raça é uma categoria ligada ao poder, e a classificação de pessoas é flutuante, podendo ser alterada de acordo com a época e o local. Contudo, se olharmos a história, há um sistema racial que sempre coloca mulheres negras como 'inferiores' em comparação a todas as mulheres não negras, ainda que aquelas ocupem posições de destaque, de prestígio e de projeção, como são os casos da atriz e da jornalista mencionadas neste estudo.

Em pleno século XXI, com todos os recursos tecnológicos de última geração e de interatividade, e a despeito dos avanços dos debates/discursos de negritude e das políticas afirmativas que visam valorizar pessoas negras, um sistema que regulariza a questão racial e busca construir a raça negra como 'inferior' e 'desumanizada' ainda persiste. A luta, como se pode perceber, é longa, dolorosa e, por diversas vezes, extremamente nociva.

Baseados em Bento (2002), podemos dizer que "a discriminação racial teria como motor a manutenção e a conquista de privilégios de um grupo sobre outro, independente do fato de ser intencional ou apoiada em preconceito" (p. 28). Assim, as agressões sofridas pelas duas mulheres nos fazem refletir que, apesar de muitas transformações no mundo contemporâneo, para parte da população brasileira, as pessoas negras não podem usufruir de qualquer direito à ascensão social. No imaginário de algumas pessoas brasileiras, a projeção sociointelectual é um privilégio a ser guardado exclusivamente para pessoas brancas (p.52). Quando essas pessoas agem no mundo por meio da linguagem e põem em prática o exercício do poder que historicamente lhes tem sido assegurado, todo o racismo estruturante que regula a sociedade brasileira se torna presente, vindo à tona uma de suas faces e revelando sua crueldade.

\section{Considerações finais}

Embora estejamos há séculos discutindo a questão racial brasileira, não é difícil nos depararmos com discursos, com valores e com memórias que sinalizam o quão estrutural e estruturante é o racismo. A desumanização de mulheres negras, fato que se repete na atualidade e, em especial, nas redes sociais, pode ser percebida nos atos de fala performativos, isto é, uma das faces da iterabilidade, apresentados ao longo do artigo. 
A linguagem como performance em seu processo de iterabilidade nos mostra que a repetição de valores, de crenças, de discursos e de memórias sobre as pessoas negras insistem em construir social, histórica, cultural, discursiva e performativamente os corpos de mulheres negras como 'inferiores' e 'animalescos'. Por mais que essas mulheres adentrem os espaços em geral apenas destinados às e ocupados por pessoas brancas, o fato de serem mulheres negras é uma marca presente nas práticas sociais, cujos corpos podem ser, segundo essa lógica, difamados, agredidos e violentados de diversas formas, porque tais ações são 'naturais' e/ou 'inerentes' às pessoas descendentes de negras e negros trazidos(as) de países africanos para trabalhos escravos.

Por outro lado, a branquidade, por intermédio dos pactos que estabelece, protege os corpos das pessoas ofensoras/agressoras, legitimando-os como 'naturalmente superiores', amenizando os efeitos de suas ações, e dando-lhes o 'direito' de expor/agredir os corpos e as vidas de mulheres negras, mesmo diante das leis mencionadas anteriormente. Nesse sentido, torna-se ímpar considerar as pessoas brancas como racializadas e tal raça como aquela que define e dita as normas raciais para negros e não-negros; assim como o masculino rege as questões de gênero.

No início deste artigo, citamos uma entrevista com antropólogo Kabengele Munanga que, naquele momento, afirmou que não se sente o preconceito racial ao se chegar ao Brasil, porque aqui "o racismo é um crime perfeito" (RAMOS; FARIA, 2012, não paginado), pois não deixa pistas. Sete anos depois, este artigo traz análise de trocas de mensagens on-line compostas por injúrias raciais e de gênero, cujos índices linguísticos buscamos identificar. Esses, por sua vez, sinalizam a (re)produção de manifestações racistas e contra as mulheres negras, e nos permitem concluir que o "preconceito reativo: o preconceito contra o preconceito de ter preconceito" (Florestan FERNANDES; João Batista PEREIRA; Oracy NOGUEIRA, 2005-2006, p. 173), o racismo como crime perfeito, que não deixa marcas, e o mito da democracia racial caíram por terra, ao menos nas relações raciais travadas na rede social estudada.

\section{Referências}

AUSTIN, John Langshaw. Quando dizer é fazer: palavras e ação. Trad. Danilo Marcondes de Souza Filho. Porto Alegre: Artes Médicas, [1962] 1990.

BARBOZA, Luiz Filipe; ALVES, Marcelo. "Dez casos de racismo que envergonham o futebol". O Globo [online]. Rio de Janeiro, s/d. Disponível em https://infograficos.oglobo.globo.com/esportes/dez-casosde-racismo-que-envergonham-o-futebol.html. Acesso em 17/08/2017.

BENTO, Maria Aparecida Silva. "Branqueamento e Branquitude no Brasil”. In: CARONE, Iray; BENTO, Maria Aparecida Silva (Orgs.). Psicologia social do racismo. Petrópolis/RJ: Vozes, 2002. p. 25-58.

BRASIL. Constituição da República Federativa do Brasil de 1988. [online] Brasília: Supremo Tribunal Federal, Secretaria de Documentação, 2017. Disponível em http://www. stf.jus.br/arquivo/cms/ legislacaoConstituicao/anexo/CF.pdf. Acesso em 17/08/2017.

BRASIL. Lei n. 1.390, de 3 de julho de 1951. Brasília, DF, 1951. Disponível em http:// www2.camara.leg.br/legin/fed/lei/1950-1959/lei-1390-3-julho-1951-361802-normaatualizadapl.pdf. Acesso em 17/08/2017.

BRASIL. Lei n. 9.394, de 20 de dezembro de 1996. Brasília, DF, 1996. Disponível em http:// www.planalto.gov.br/ccivil_03/leis/L7716.htm. Acesso em: 17/08/2017.

BRASIL. Lei n. 10.634, de 9 de janeiro de 2003. Brasília, DF, 2003. Disponível em http:// www.planalto.gov.br/ccivil_03/leis/2003/L10.639.htm. Acesso em 17/08/2017.

BRASIL. Projeto de Lei do Senado n. 80, de 2016. Brasília, DF, 2016. Disponível em http:// www.senado.gov.br/sf/atividade/materia/getTexto.asp?t=188845. Acesso em 17/08/2017.

BUTLER, Judith. Excitable speech: a politics of the performative. New York: Routledge, 1997.

BUTLER, Judith. Problemas de gênero: feminismo e subversão da identidade. Trad. Renato Aguiar. Rio de Janeiro: Civilização Brasileira, [1990] 1999.

BUTLER, Judith. Quadros de guerra: quando a vida é passível de luto? Trad. Sérgio Lamarão e Arnaldo Marques da Cunha. Rio de Janeiro: Civilização Brasileira, [2009] 2015.

CRENSHAW, Kimberlé. "Documento para o Encontro de Especialistas em Aspectos da Discriminação Racial Relativa a Gênero". Trad. Liane Schneider. Revista Estudos Feministas, Florianópolis, v. 10, n. 1, p. 171-188, jan./jun. 2002. 
DAVIS, Angela. Mulheres, raça e classe. Trad. Heci Regina Candiani. São Paulo: Boitempo, [1981] 2016.

DERRIDA, Jacques. Limited Inc. Evanston: Northwestern University Press, [1977] 1988.

DURBAN. Declaração e Programa de Ação adotados em 8 de setembro de 2001 na III Conferência Mundial de Combate ao Racismo, Discriminação Racial, Discriminação Racial, Xenofobia e Intolerância Correlata. Durban, África do Sul, 2001. Disponível em http://www.unfpa.org.br/Arquivos/ declaracao_durban.pdf. Acesso em 17/08/2017.

FANON, Frantz. Pele negra, máscaras brancas. Trad. Renato da Silveira. Salvador: EDUFBA, [1952] 2008.

FERNANDES, Danúbia de Andrade. "O gênero negro: apontamentos sobre gênero, feminismo e negritude". Revista Estudos Feministas, Florianópolis, v. 24, n. 3, p. 691-713, set./dez. 2016.

FERNANDES, Florestan; PEREIRA, João Batista; NOGUEIRA, Oracy. "A questão racial brasileira vista por três professores". Revista USP, n. 68, p. 168-179, dez./fev. 2005-2006.

GOMES, Nilma Lino. "Movimento negro e educação: ressignificando e politizando a raça". Educação Sociedade, v. 33, n. 120, p. 727-744, jul./set. 2012.

GOMES, Nilma Lino. "Cabelo e cor da pele: uma dupla inseparável”. In: BARBOSA, Lúcia Maria de Assunção; GONÇALVES E SILVA, Petronilha Beatriz; SILVÉRIO, Valter Roberto (Orgs.). De preto a afrodescendente: trajetos de pesquisa sobre relações étnico/raciais no Brasil. São Carlos: Editora UFSCAR, 2003. p. 137-150.

HALL, Stuart. Da diáspora: identidades e mediações culturais. Trad. Adelaine La Guardia Resende et al. Belo Horizonte: Editora UFMG, 2003.

HINE, Christine. Virtual ethnography. London: Sage Publications, 2000.

HINE, Christine. Virtual methods: issues in social research on the internet. Oxford: Berg Publishers, 2005.

hooks, bell. "Mulheres negras: moldando a teoria feminista". Trad. Roberto Cataldo Costa. Revista Brasileira de Ciência Política, n. 16, jan./abr., p. 193-210. 2015.

hooks, bell. Teaching to Trangress: education as the practice of freedom. New York: Routledge, 1994.

KERNER, lan. "Tudo é interseccional? Sobre a relação entre racismo e sexismo". Trad. Bianca Tavolari. Novos Estudos, n. 93, jul. 2012.

MARQUES, Eugenia Portela Siqueira; SILVA, Wilker Solidade da. (Org.). Educação, Relações ÉtnicoRaciais e Resistência: as experiências dos Núcleos de Estudos Afro-brasileiros e Indígenas no Brasil. 1ed. SP: Triunfal Gráfica e Editora, 2016, v. 1, p. 39-58.

MBEMBE, Achille. Crítica da Razão Negra. Trad. Marta Lança. Lisboa: Antígona, [2013] 2014.

MOITA LOPES, Luiz. Paulo. "Pesquisa interpretativa em linguística aplicada: a linguagem como condição e solução'. Delta, São Paulo, v. 10, n. 2, p. 329-338, 1994.

MORAES, Fabiana. No país do racismo institucional: dez anos de ações do GT Racismo no MPPE. Recife: Procuradoria Geral de Justiça, 2013.

MUNANGA, Kabengele. "Uma abordagem conceitual das noções de raça, racismo, identidade e etnia". In: BRANDÃO, Augusto P. (Org.). Cadernos PENESB 5 - Programa de educação sobre o negro na sociedade brasileira. Niterói/RJ: EdUFF, 2004. p. 15-34.

PENNYCOOK, Alastair. Global Englishes and transcultural flows. New York: Routledge, 2007.

PINTO, Joana Plaza. "Conexões teóricas entre performatividade, corpo e identidades". DELTA: Documentação de Estudos em Linguística Teórica e Aplicada, v. 23, n 1, p. 1-26. 2007.

RAMOS, Camila Souza; FARIA, Glauco. "Nosso racismo é um crime perfeito. O antropólogo Kabengele Munanga fala sobre o mito da democracia racial brasileira, a polêmica com Demétrio Magnoli e o papel da mídia e da educação no combate ao preconceito no país". In: Revista Fórum [online]. 
Entrevista postada em 09 fev. 2012. Não paginado. Disponível em https://www.revistaforum.com.br/ 2012/02/09/nosso-racismo-e-um-crime-perfeito/. Acesso em 17/08/2017.

RAMPTON, Ben. "Continuidade e mudança nas visões de sociedade em linguística aplicada". In: MOITA LOPES, Luiz Paulo da (Org.). Por uma linguística aplicada INdisciplinar. São Paulo: Parábola, 2006. p. 109-128.

RUBIN, Gayle. Deviations: a Gayle Rubin reader. Durhan \& London: Duke University Press, 2011.

SCHUCMAN, Lia Vainer. Entre o encardido, o branco e o branquíssimo: branquitude, hierarquia e poder na cidade de São Paulo. São Paulo: Annablume, 2014.

SCOTT, Joan Wallach. "Gênero: uma categoria útil de análise histórica". Trad. Guacira Lopes Louro [1990], rev. Tomaz Tadeu da Silva [1995]. Educação \& Realidade, v. 20, n. 2, jul./dez. p. 71-99. [1986] 1995.

SILVA, Carolina Parreiras. Sexualidades no ponto.com: espaços e homossexualidades a partir de uma comunidade 'on-line'. 2008. Dissertação (Mestrado em Antropologia Social) - Departamento de Antropologia Social, Instituto de Filosofia e Ciências Humanas da Universidade Estadual de Campinas, Campinas, SP.

SILVERSTEIN, Michael. Language and the culture of gender: At the intersection of structure, usage and ideology. In: MERTZAND, Elizabeth; PARMENTIER Richard (Eds.). Semiotic Mediation: Sociocultural and Psychological Perspectives. New York: Academic Press, 1985. p. 219-259.

SOARES, Luís. "Alunos negros da Unesp sofrem racismo: 'sem cotas para animais africanos'". Pragmatismo Político [online], 19/04/2012. Disponível em https://www.prag matismopolitico.com.br/ 2012/04/alunos-negros-da-unesp-sofrem-racismo-sem-cotas-para-animais-africanos.html. Acesso em 17/08/2017.

SUPREMO TRIBUNAL FEDERAL. "STF julga constitucional política de cotas na UnB". Notícias STF [online], 26/04/2012. Disponível em http://www.stf.jus.br/portal/cms/verNoti ciaDetalhe.asp?idConteudo=\% 20206042. Acesso em 17/08/2017.

VENTURI, Gustavo; TURRA, Cleusa (Orgs.). Racismo Cordial - Folha de São Paulo/Datafolha: A mais completa análise sobre o preconceito de cor no Brasil. São Paulo: Ática, 1995.

WEISSHEIMER, Marco. "Agressores de estudante indígena da UFRGS já estão identificados, diz advogado". Sul 21 [online], 24/03/2016. Disponível em https://www.sul 21 .com.br/jornal/agressoresde-estudante-indigena-da-ufrgs-ja-estao-identificados-diz-advogado/. Acesso em 17/08/2017.

Roberto Carlos da Silva Borges (borgesrcs@gmail.com) coordena o Programa de Pósgraduação stricto sensu em Relações Étnico-Raciais (PPRER). Leciona no Departamento de Línguas Estrangeiras Aplicadas às Negociações Internacionais (LEANI) e no Programa de Pós-Graduação em Relações Étnico Raciais (PPRER), do CEFET/RJ. É pós-doutorado em Comunicação (ECO/UFRJ), doutor em Estudos da Linguagem (UFF), mestre em Língua Portuguesa (UERJ); especialista em Língua Portuguesa (UFRJ) e graduado em Língua Portuguesa e Respectivas Literaturas (FAHUPE). Atua na área Interdisciplinar, com foco nas práticas identitárias em mídias fílmicas, no Ethos, nas relações raciais, raça e racismo.

Glenda Cristina Valim de Melo (glendamelo09@gmail.com) é Professora adjunto de Língua Inglesa e Língua Portuguesa, docente permanente do Programa de Pós-Graduação em Memória Social, na Universidade Federal do Estado do Rio de Janeiro. Finalizou o pós-doutoramento em Linguística Aplicada na Universidade Federal do Rio de Janeiro, atua nas áreas de práticas identitárias (raça, gênero e sexualidade) e discurso e coordena os projetos Indexicalidades e Performances Discursivas: Raça, Gênero e Sexualidade em Contexto on/off-line e Trajetórias, Indexicalidades e Performances Discursivas de Raça Gênero e Sexualidade em Contextos On/ Offline. 


\section{COMO CITAR ESSE ARTIGO DE ACORDO COM AS NORMAS DA REVISTA}

BORGES, Roberto Carlos da Silva; MELO, Glenda Cristina Valim de. "Quando a raça e o gênero estão em questão: embates discursivos em rede social". Revista Estudos Feministas, Florianópolis, v. 27, n. 2, e54727, 2019.

\section{CONTRIBUIÇÃO DE AUTORIA}

Todo o trabalho (concepção, coleta de dados e análise de dados, elaboração do manuscrito, redação, discussão de resultados) foi produzido em total parceria.

\section{FINANCIAMENTO}

Não se aplica.

\section{CONSENTIMENTO DE USO DE IMAGEM}

Não se aplica.

APROVAÇÃO DE COMITÊ DE ÉTICA EM PESQUISA

Não se aplica.

\section{CONFLITO DE INTERESSES}

Não se aplica.

LICENÇA DE USO

Este artigo está licenciado sob a Licença Creative Commons CC-BY Internacional. Com essa licença você pode compartilhar, adaptar, criar para qualquer fim, desde que atribua a autoria da obra.

\section{HISTÓRICO}

Recebido em 02/01/2018

Reapresentado em 07/08/2018

Aprovado em 21/08/2018 